\title{
INTERCULTURALIDADE: POR UMA GENEALOGIA DA DISCRIMINAÇÃO
}

\author{
Maria Beatriz Rodrigues \\ Lavagna (GE), Itália
}

RESUMO: O tema interculturalidade não pode ser examinado sem o devido referimento às lutas por reconhecimento de identidades e de direitos. Hoje, especialmente depois da queda do muro de Berlim, e do propalado fim das ideologias, e mais recentemente após o 11/09/2001, observa-se um recrudescimento dessas lutas através de discursos étnicoreligiosos. Associa-se a isso o crescente movimento migratório de pessoas verso países mais desenvolvidos, que alguns atribuem a globalização, outros aos próprios conflitos étnico-religiosos, ou a pobreza endêmica resultante do sistema político-econômico neoliberal. Acreditamos que todos estes fatores são indissociáveis e que compõem a realidade social contemporânea, com seus movimentos de exclusão direcionados a novos grupos. Este artigo reflete genealógicamente sobre diversidade e convivência intercultural, tentando entender as implicações e significados da discriminação hoje, em um contexto de crescente intolerância étnica, cultural e religiosa. Para tanto, utilizamos a experiência de Foucault com a revolução de Khomeini no Irã, entre 1978-79, como dispositivo inaugural da discussão sobre o hoje chamado "choque de civilizações". Utilizamos também exemplos atuais, muitos deles extraídos de nossa vivência como subjetividade imigrante na Europa.

PALAVRAS-CHAVE: Interculturalidade; diversidade; globalização; identidade; discriminação.

\section{INTERCULTURALITY: \\ FOR A GENEALOGY OF DISCRIMINATION}

ABSTRACT: Interculturality cannot be examined without referring to the struggles for identity and recognition of rights. Today, after the fall of the Berlin wall, and the gabber of the end of ideologies and, more recently, since $9 / 11$, the world has witnessed an increase of these struggles through ethnical and religious discourses. Associated to this is the increasing migratory flow of people towards the developed countries triggered, according to many, by phenomena such as globalization, ethnic conflicts and endemic poverty caused by neo-liberalism. We believe that all these factors are tied together and that they make up today's social reality, with its toll of exclusion and discrimination to be paid by the newcomers. This article focuses on diversity and multicultural cohabitation and tries to grasp, genealogically, the meanings and effects of discrimination today. It uses Foucault's interviews and texts between 1978-79 about his direct involvement with Khomeini's Iranian Revolution. This material, together with many contemporary examples extracted from the author's subjectivity as an emigrant in Europe, serves as an inaugural vehicle to discuss ethnical, cultural and religious intolerance, in the background of the so called "clash of civilizations".

KEYWORDS: Interculturality; diversity; globalization; identity; discrimination.

\section{Diversidade e Discriminação}

A diversidade está no centro das principais discussões sociais e políticas. Do final dos anos $60,{ }^{1}$ mas em especial a partir da década de 80 , os movimentos das chamadas minorias têm crescido e adquirido um progressivo reconhecimento nos países ocidentais. Desde então, o mundo assistiu a muitas lutas por reconhecimento de identidades, com processos e resultados diversos. Os anos 80 viram afirmar-se o "políticamente correto", onde as manifestações mais explícitas de discriminação são patrulhadas através de uma linguagem muito controlada. Segundo Eco (2006, p. 91) o termo nasceu nos Estados Unidos, em uma sentença da corte americana em 1793, sobre o uso da palavra Estado para designar o povo para o qual o Estado existe. Esse uso indevido foi julgado "not politically correct”. Dois séculos depois, entre 1980-90, a expressão foi reeditada por movimentos que denunciavam o uso de palavras de conotação discriminatória.

As transformações sociais mais significativas das décadas de 80 e 90 foram o fim do comunismo e das ideologias. Estas transformações, por um lado, impulsionaram novas buscas de identidade em decorrência do relaxamento de proibições políticas e religiosas. Por outro lado, as mesmas contribuiram para o incremento de movimentos migratórios de pessoas em busca de novas oportunidades de vida em países ricos. A convivência intercultural desafia principalmente países europeus e os Estados Unidos.

Cultura se transformou em sinônimo de identidade, um indicador e um diferenciador de identidade. Naturalmente, a cultura sempre foi um sinal de distinção social; o que é novo é que os grupos que se formam em torno a esses indicadores de identidade reivindicam ao Estado e as suas agências o reconhecimento 
legal e recursos para preservar e proteger suas especificidades culturais. A política de identidade arrasta o Estado em guerras culturais e, como conseqüência das mesmas, o próprio conceito de cultura mudou (Benhabib, 2005, p. 17).

As lutas por reconhecimento de identidades culturais têm sido direcionadas para bases étnico-religiosas, vide exemplos de divisões de Estados como a Iugoslávia e, mais recentemente, revoluções e guerrilhas em países Orientais, na maioria islâmicos, como Paquistão, Chechênia e Afeganistão. As reivindicações têm crescido em violência e intolerância, sendo o 11/9/2001 o divisor de águas contemporâneo dessas lutas. $\mathrm{O}$ aniquilamento coletivo, o pânico e a depressão que o seguiram, provocaram um acirramento de defesas com várias conseqüências, entre elas, leis antiterrorismo muito restritivas que desconsideram direitos de privacidade em nome da segurança, como por exemplo o "Patriot Act"2 aprovado nos Estados Unidos imediatamente após os ataques. Igualmente significativa foi a radicalização de costumes visando a reafirmação de identidades e pertencimentos, como a crescente influência da igreja em decisões políticas, que discutiremos posteriormente. Como coloca Lerner (2005), nunca se falou tanto em tradições, em cultura, em preservação.

Os ataques terroristas criaram o que pode ser chamado de "islamofobia", em parte estimulada pelo tratamento político internacional dado a questão, em parte pela difusão de teorias como “Clash of civilizations?” (Huntington, 1993). A tese central desse autor é que as questões culturais e de identidade religiosa assumiram o primeiro lugar como causa de conflitos no mundo pós-guerra fria. Todas estas reações e medidas produziram a imagem do muçulmano como um inimigo, alguém que odeia o Ocidente e está sempre pronto a atacá-lo.

Discriminação é um tratamento desigual dirigido a indivíduos ou grupos por pertencerem a categorias específicas. Alguns exemplos de discriminação são o racismo, o sexismo e a homofobia, mas são sempre produzidos novos, como a "islamofobia" acima referida. A discriminação supõe um tratamento diferenciado em ausência de justificativas plausíveis ou de consenso social. Por exemplo, a idade mínima para dirigir um automóvel é um consenso social mas a idade usada como requisito para ser admitido em uma empresa é discriminatória. Discriminação é um conceito dinâmico, uma linha móvel, que depende de tempo e lugar, pois as mesmas situações em diferentes períodos históricos ou em culturas diferentes são consideradas aceitáveis ou não. A escravidão era aceita no passado e justificada pela convicção de que certas etnias eram inferiores a outras. Essa hierarquização das diferenças foi gradativamente conscientizada e combatida através de movimentos sociais.
As legislações internacionais sobre discriminação são decorrentes da "Declaração Universal dos Direitos $\mathrm{Hu}$ manos", elaborada pela Organização das Nações Unidas (ONU) e sancionada em 1948. A declaração defende o respeito a cada indivíduo, independente de religião, etnia, sexo, língua, opiniões políticas, e serve como referência para a convivência civil. A partir da mesma, cada país elabora suas próprias leis de combate à discriminação ou de defesa da diversidade. Atualmente muitos países adotam as chamadas políticas de discriminação positiva, ou affirmative actions, mais conhecidas como quotas de participação social reservadas a grupos específicos.

Discriminação é freqüentemente associada ao racismo, porém, como referido acima, o racismo é uma face da discriminação que não esgota a complexidade do tema. Racismo, segundo Jelloun (1998, p. 9), consiste em manifestar desconfiança, ou até mesmo desprezo, por pessoas que possuem características físicas e culturais diferentes das nossas. A discriminação está na base de nosso cotidiano, pertence a ordem das escolhas que devemos continuamente fazer. Discriminação é também, como a entendemos, derivada daquele conjunto de atitudes e sentimentos que nos faz sentir mais certos ou mais potentes do que outros sujeitos e que nos impulsiona a perseverar em opiniões e conceitos mesmo prescindindo da verdade. Em outras palavras, discriminação é inscrita na ordem da razão mas também na das paixões, diz respeito ao quanto nossos pontos cegos e vulneráveis, sob a influência definitiva de nosso véu de crenças e preconceitos, nos tolhem a capacidade de perceber a realidade mais objetivamente. Quanto mais convencidos de uma verdade ou de uma escolha, menor será a nossa capacidade de aceitar outras opiniões e argumentos. Nestes casos, a discriminação, ou a escolha de um caminho em detrimento de outros, é levada ao extremo, a um ponto de não retorno e ali certamente encontramos o sectarismo, o dogmatismo, a prepotência, entre outras atitudes e sentimentos de intolerância.

O que a diversidade e a discriminação têm a ver com a experiência de Foucault na Revolução Iraniana há quase três décadas atrás? Em primeiro lugar, a revolução iraniana recolocou a religião no centro da atenção política em escala mundial. É, portanto, um dispositivo inaugural da construção ideológica e mediática chamada "choque de civilizações", que constantemente nos convida a tomar partido e a erigir preconceitos sobre os que se diferenciam de nossas concepções de mundo. Em segundo lugar, como discutiremos através de vários exemplos, a discriminação tem assumido uma dobra extrema, radical, assim como os significados de identidade, cultura e credo. Em terceiro lugar, sendo a genealogia um método que permite individualizar a origem dos discursos, sem postular uma ordem necessária ou um sentido unitário de história, ela pode nos ajudar a reconstruir ou a tentar dar sentido à problemática colocada neste artigo. 


\section{Notas sobre a Viagem de Foucault à Pérsia}

Trata-se de uma revolução ocorrida entre 1978-79, em um país oriental, o Irã, para depor o regime autoritário de seu monarca, o Xá Reza Pahlavi, que posteriormente se transformou em uma teocracia islâmica. Essa realidade foi interpretada por um filósofo ocidental que vivia em uma sociedade polarizada pela disputa ideológica entre Estados Unidos e União Soviética. Acreditamos que a revolução iraniana demonstrou ser um dos primeiros sinais de descontinuidade da citada disputa ideológica. Além disso, Foucault como pensador estava entre o que se convencionou chamar terceira (1969-1979) e quarta (19801984) sínteses de seu pensamento e, nesse aprimoramento de idéias, o autor transita entre o poder como disciplina do corpo e suas interfaces com formas de resistência, e o sujeito moral, capaz de se autoconstituir e transformar continuamente as experiências. O poder passa de uma posição mais circunscrita para outra em que é uma batalha sempre inconclusa, onde o sujeito não tem outra alternativa do que tentar influenciar os resultados, tomando parte ativa na dinâmica do poder.

O material que escolhemos para a análise foi produzido no período em que o autor visitou o Irã e acompanhou os acontecimentos in loco. É uma escolha intencional e, portanto, discriminatória de sua vasta e profícua produção intelectual. O que nos interessa neste artigo são as suas considerações sobre aquele episódio específico, para fundamentar nossa leitura de acontecimentos contemporâneos. A visão de Foucault sobre o período lança luz sobre o que aconteceu após a insurreição iraniana no mundo islâmico e em suas interfaces com o Ocidente.

Inicialmente, Foucault parecia não ter encontrado o que esperava daquele evento inusitado, ou seja, a capacidade do poder e da resistência de transformar subjetividades, a capacidade da política de envolver mudanças de vida e romper com padrões estabelecidos de organização social. $\mathrm{O}$ autor chegou a afirmar que não acreditava na ascensão política de Khomeini. ${ }^{3}$ Em decorrência, voltouse para questões como a filosofia de vida e religiosa xiita, tentando explicar como a política naquele contexto era autoritária mas, ao mesmo tempo, baseada em questões do "espírito", cunhando inclusive a expressão "espiritualidade política” (Cavazzini, 2005b, p. 13). Por posições como esta, Foucault foi acusado de ter acolhido com entusiasmo os acontecimentos no Irã.

$\mathrm{O}$ autor deixa clara sua perplexidade quanto aos rumos do movimento e de suas interfaces com outros atores políticos, assim como com a conotação religiosa fortemente incitada e acolhida nacionalmente. Principalmente dois pontos o intrigavam: a ausência de luta de classes ou de um conflito social que justificasse a revolução; e a ausência de uma vanguarda política, de um partido ou de uma ideologia, que conduzisse a luta. ${ }^{4} \mathrm{~A}$ revolta dos iranianos não propunha uma agenda clara em termos econômicos e sociais, além da queda do monarca Reza Pahlavi, e o prêmio por arriscar a vida na luta contra o poder era colocado no além, na recompensa de morrer para instaurar um governo messiânico. Todos esses elementos eram emoldurados por uma forte revivência de tradições que assinalava a possibilidade do movimento se transformar em uma ditadura teocrática (Cavazzini, 2005a, p. 24; Foucault, 2000a, p. 440). Um exemplo claro era o uso voluntário do véu por parte das mulheres, que representava um símbolo contra o regime filo-ocidental do Xá e, ao mesmo tempo, uma tomada de posição a favor do retorno às tradições islâmicas. Aquela escolha, do então chamado "véu político", tornou-se compulsória e seu significado atual não é mais de rebelião.

Para qualquer um que não procurava as 'razões de base' para o movimento no Irã, mas que estava atento ao modo como era vivido; para qualquer um que tentava entender o que estava acontecendo nas mentes daqueles homens e mulheres quando arriscavam suas vidas, algo surpreendia. Eles inscreviam suas humilhações, seu ódio pelo regime, e sua determinação de depô-lo, entre as fronteiras do paraíso e da terra, em uma visão histórica que era religiosa tanto quanto política (Foucault, 2000b, p. 450).

Hoje pode parecer fácil entender a sucessão de eventos desde a revolução iraniana até o estabelecimento do islamismo militante como opositor do Ocidente (vide a formação de grupos como Al Qaeda, Talebã, Hamas, etc). Porém, mesmo para Foucault, a leitura dos eventos iranianos naquele momento histórico era difícil e uma tomada de posição custava inclusive credibilidade. Sua surpresa e incredulidade explicavam o ineditismo dos acontecimentos, principalmente porque as explicações de base racionais-iluministas, norteadoras das revoluções francesa e russa, não bastavam para decodificar o que estava sendo produzido. Ninguém melhor do que um desconstrutivista para testemunhar, e ler sem pré-concepções, a gênese de algo inusitado e que, posteriormente, marcaria a história como o primeiro exemplo contemporâneo de regime islâmico fundamentalista.

É importante também considerar outros aspectos daquele momento histórico, de plena crise ideológica do marxismo devido ao desencantamento com a experiência comunista da União Soviética. Uma década depois, o bipolarismo estaria terminado com a queda do muro de Berlim e seria inaugurada a supremacia do neoliberalismo norte americano e da globalização. Uma grande transformação social se estava processando e as convicções políticas e ideológicas, até então aceitas, não serviam mais para explicar a realidade. Sem o apoio do hermético re- 
gime político da União Soviética, países balcânicos e do leste europeu tiveram seu empobrecimento econômico e outras mazelas reveladas, ficando à mercê de guerras étnicas e religiosas. Iniciou-se um verdadeiro êxodo de pessoas que buscavam refúgio em países vizinhos da Europa ocidental. A globalização e sua concentração de renda sem precedentes, empurrou grandes massas de população de todos os continentes verso países desenvolvidos.

Em linhas muito gerais esse quadro configurou a atual interculturalidade na Europa. Mas algo mais abrangente estava sucedendo, como herança do fenômeno presenciado por Foucault, ou seja, o islamismo militante estava tomando proporções até então desconhecidas. Como já afirmado, a teocracia iraniana, que recolocou a religião no centro da política, abriu espaço para a expansão do integralismo religioso. A formação de gerações de muçulmanos em diferentes países a partir de uma concepção muito restritiva da religião, fez com que diferenças em relação à vida ocidental emergissem com a crescente convivência intercultural.

\section{Quase 30 Anos Depois: Diversidade e Interculturalidade Hoje}

Tendo em vista nossa intenção de discutir a intolerância étnico-religiosa, conceituamos e estabelecemos relações entre diversidade cultural e discriminação. Buscamos pontos de contato desses conceitos com a revolução iraniana, que consideramos o dispositivo que modificou características importantes da convivência intercultural, através da desecularização da política e da vida pública. Tentaremos relacionar essa gênese com exemplos atuais de discriminação intercultural, vividos por nós ou através da mídia, na Itália e na Grã-Bretanha.

Dados de pesquisa em três nações, França, Holanda e Grã-Bretanha, demonstram que reivindicações de grupos minoritários acontecem independentemente do tipo de políticas nacionais de aceitação e negociação de diferenças culturais. Ao mesmo tempo, esses dados constatam que nas nações referidas os grupos autodenominados muçulmanos ou islâmicos representam a maioria das reivindicações. Isso demonstra, segundo os autores, que as reivindicações de grupos culturalmente diferentes em países europeus não significa controvérsia per se, mas que existem pontos de atrito muito claros entre o Islam e as políticas liberais dos países ocidentais (Koopmans, Statham, Giugnim \& Passy, 2005, p. 174). Constatações como essas têm levado autores a sustentar que a integração de povos islâmicos em outros paises é mais difícil e isso se deve, preponderantemente, a não separação entre política e religião, característica intrínseca da religião muçulmana (Koopmans et al., 2005, p. 148; Sartori, 2007, p. 127).

Fala-se do véu (chador) e vestido (burqa) islâmicos, do papel subalterno da mulher, submetida aos ditames religiosos e confinada a um lugar de não-ser, como sinônimos de conservadorismo. Porém, vemos que as religiões ocidentais também assumiram uma dobra mais integralista através da radicalização da moral e dos costumes. Uma diferença significativa entre fiéis islâmicos e católi$\cos ^{5}$ é que os primeiros parecem mais prontos a seguir as imposições religiosas, pois a religião muçulmana entra mais profundamente na esfera privada de seus fiéis. Os católicos aprenderam a conviver com a religião de uma maneira mais livre e a interpretar seus ditames conforme, e a partir de, suas exigências pessoais. Por exemplo o divórcio, o sexo antes do casamento, o aborto, são práticas recriminadas pela igreja mas presentes em sociedades de maioria católica como a Itália e a Espanha. Mesmo assim, não podemos pensar que certas doutrinas ou decisões canônicas não influenciem a vida cotidiana das pessoas.

O revisionismo religioso atual está provocando um retrocesso de algumas conquistas sociais, atingindo sobremaneira a família e, centralmente, a mulher que vê muitas de suas conquistas de independência questionadas. A inseminação artificial na Itália, por exemplo, é praticamente impossível de ser realizada devido à rigidez das regras estabelecidas por uma lei recentemente aprovada. Os óvulos ou o sêmen devem pertencer as próprias pessoas envolvidas no tratamento, as manipulações de laboratório e a implantação dos óvulos são permitidas somente se de forma não invasiva, conceito muito difícil de ser definido quando se refere a esse tipo de prática médica. As restrições quanto ao armazenamento ou destruição dos óvulos é outra questão que dificulta ou até impede a prática. $\mathrm{Na}$ ocasião do referendum para aprovação de uma lei contrária àquela em vigor, a igreja interferiu ativamente solicitando aos fiéis de não votar. O "não-voto" ${ }^{6}$ invalida o referendum, que resulta abaixo do percentual necessário de $50 \%+1$ dos eleitores e, neste caso específico, significou o poder da igreja de interferir na participação política dos cidadãos e de boicotar um dispositivo democrático de expressão popular.

Outro exemplo de disputa religiosa refere-se a uma causa judiciária impetrada por uma associação que defende a laicidade do Estado, referida em um outro artigo (Rodrigues, 2005), que reivindicava a retirada de símbolos religiosos das escolas públicas italianas. A causa foi julgada em março de 2006 e a decisão foi a favor da permanência dos crucifixos nas salas de aula. Segundo a sentença, os crucifixos não representam apenas um credo religioso e sim:

um símbolo idôneo que exprime o elevado fundamento dos valores cívicos, como a tolerância, o respeito recíproco, a valorização da pessoa e a afirmação de seus direitos... que são os valores que delineiam a atual organização laica do Estado. ${ }^{7}$

Porém, os valores cívicos ou o respeito recíproco não bastaram para apreciar mais detidamente a solicitação de 
pessoas de outras culturas e credos, ou para adequar os históricos princípios de tolerância à realidade social atual. Freqüentemente ocorrem julgamentos em diferentes países europeus sobre o uso de véus e vestes tradicionais em recintos públicos.

Da mesma forma que o revisionismo religioso, o revisionismo histórico é utilizado para sustentar teorias discriminatórias. Um exemplo é a chamada "Padania", região que não existe formalmente e que foi idealizada pelo movimento político italiano de conotação racista, Lega Nord. Este movimento defende a divisão do país e a "liberação" do povo padano da centralidade de Roma e do atraso do sul do país. Na defesa dessas reivindicações são colocadas em pauta raízes célticas, são desenvolvidos rituais para suportar as crenças, como beber a água do Rio Po, que banha a região da real Pianura Padana ${ }^{8}$ e são organizadas patrulhas noturnas para a caça de clandestinos na região. Outro exemplo recente, mas infelizmente não inédito, foi a negação do holocausto por parte do escritor inglês David Irving, condenado em 2006 na Áustria. $\mathrm{O}$ atual presidente do Irã, Ahmadinejad, rejeita o holocausto e professa a destruição do povo hebraico.

Crouch (2003, p. 130) coloca que uma identidade social se forma através de grupos de vanguarda que propõem lutas e agregam pessoas as suas causas, como por exemplo, os reconhecidos movimentos feministas e ecológicos. Esses movimentos provocam ressonância social e passam a ser incorporados na linguagem e no imaginário coletivo, quando porções do grande público aderem as suas causas. Uma vez difundidos, recebem atenção dos partidos políticos oficiais, que os acusam de antidemocráticos, anárquicos ou outro, pelo fato de contraporem ou colocarem em discussão questões defendidas pelos partidos. Dessa forma, um movimento identitário inaugura sua entrada na política, inicialmente como força instituinte $\mathrm{e}$, posteriormente, institucionalizado ou absorvido por um partido político.

Até os anos 90 as lutas pelo reconhecimento de identidades ou de defesa da diversidade andavam, prioritariamente, em direção à busca de igualdade. Hoje a intolerância prevalece, a supremacia de credos ou identidades sobre outros, diminuindo as possibilidades de convivência pacífica. Os países democráticos e as organizações humanitárias internacionais, como a ONU, estão longe de fornecer respostas plausíveis. Paradoxalmente, as respostas aos conflitos se manifestam através de agressões, como a guerra no Iraque, ou com a crescente adesão a partidos de conotação xenófoba, como os de Haiden na Áustria, Pim Fortuyn na Holanda, Le Pen na França, entre outros. Por outro lado, existem pessoas e movimentos que buscam pontos de contato, e que acreditam que mesmo nos países fundamentalistas, ${ }^{9}$ existe vontade de diálogo.
"Antes de ditar aos outros os nossos valores universais, seria oportuno perguntar a eles o que pensam: se admitimos que os outros não são menos humanos do que nós, as suas opiniões pesam como as nossas na balança" (Todorov, 2005, p. 44).

$\mathrm{O}$ autor citado refere-se ao chamado "direito de intervenção", defendido pelo então secretário geral da ONU, Kofi Annan, e pelo ex-Presidente dos Estados Unidos, Bill Clinton, no período da ação militar no Kosovo. Esse direito autoriza a intervenção militar por parte de países pertencentes a uma organização internacional, como a OTAN $^{10}$, em países que violam direitos humanos. Desse modo, um poderoso mecanismo de controle global foi inaugurado, sendo muitas vezes movido por suspeitas, intolerância e interesses comerciais e justificando inclusive as chamadas "guerras humanitárias". Este princípio foi ulteriormente aprofundado e etiquetado de "guerra preventiva", através do ataque unilateral ao Iraque em 2003, país que supostamente possuía armas de destruição de massa.

Outra consequiência do controle global em resposta às lutas por reconhecimento de identidades, é a restrição dos direitos de cidadãos de origem estrangeira de permanecer em países europeus se suspeito ou confirmado o envolvimento com grupos extremistas. Em fevereiro de 2006, aconteceu o julgamento e a deportação de Omar Bakri Mohammed da Grã-Bretanha, muçulmano, que comprovadamente incitava massas à intolerância e atos terroristas. Três anos atrás, Cat Stevens, ${ }^{11}$ ou Yussuf Islam, foi impedido de entrar nos Estados Unidos para participar de um evento em prol da paz mundial. No primeiro caso, as suspeitas foram abundantemente comprovadas, mas no segundo a restrição baseava-se exclusivamente na opção religiosa. Em outras palavras, especialmente após os ataques terroristas de 11/09/2001, a segurança se transformou em justificativa para a violação de direitos e privacidade. Paradoxalmente, países democráticos, especialmente europeus, escrevem continuamente leis sobre os direitos à privacidade, sempre emendadas e atualizadas. A violação da mesma parece ser inerente à contemporaneidade.

A necessidade de segurança extrapola limites geográficos, como visto acima, e é introjetada por pessoas que reagem fobicamente aos diversos culturais. Em um espaço público as pessoas que se vestem diversamente são olhadas com suspeita, seus filhos são considerados inadequados na escola ou nos parques para brincar com os meninos locais. Na Itália a assistência social tenta estabelecer formas de controle a essas famílias, em nome de um auxílio à socialização ou à escolarização. Não é raro ouvir de operadores sociais que trabalham com crianças muçulmanas, que as mesmas serão homens-bomba no futuro. A discriminação é, nestes casos, reproduzida por quem deveria servir como mediador entre as famílias e a sociedade. 
Verificam-se muitos estereótipos na convivência intercultural. Alguns grupos são olhados com curiosidade ou condescendência, originadas da certeza que não conhecem princípios básicos de convivência social. A esse propósito, uma pedagoga, referindo-se à solicitação de auxílio psicopedagógico feito por uma mãe estrangeira para seu filho, classificou de falta de "inteligência social" as dificuldades de comunicação dessa pessoa com os técnicos que avaliaram o seu caso. Essa rigidez no padrão de comportamento em situações de convivência intercultural é, muitas vezes, usada como chave de leitura para as relações sociais.

A experiência cotidiana da interculturalidade nos demonstra a importância de reconhecer diferentes culturas, pertencimentos, identidades, mantendo, porém, a clareza que essas não são realidades homogêneas e sim espaços de trocas, recursos para a ação, narrativas compartilhadas, contestadas e negociadas. A diversidade - e não a homogeneidade - distingue uma cultura vital e em contínua transformação (Benhabib, 2005, p. 31; Lanzillo, 2005 , p. 102; Mantovani, 2004, p. 8).

A discussão sobre convivência intercultural nãoé simples e arriscamos ao defender uma posição de desvendar, ou desconsiderar, outras faces da questão. Segundo Mantovani $(2004$, p. 16) dois movimentos complementares de trocas culturais coexistem na atualidade globalizada. Em primeiro lugar, as culturas chamadas centrais impõemse a outras culturas através da força do capitalismo, da mídia, do consumo e da tecnologia. Modelos culturais, valores e modos de vida "vencedores" são impostos globalmente. Esse seria um movimento migratório-cultural que parte do chamado "centro" do mundo à "periferia", ou seja, dos países mais ricos e industrializados aos mais pobres. Em segundo lugar, tratando dos movimentos migratórios contrários, ou seja, de pessoas que partem da "periferia" em direção ao "centro", verifica-se o acirramento de lutas por reconhecimento de identidades minoritárias. Os resultados dessas lutas são os mais diversos e as respostas dadas pelos países receptores podem ser do tipo "multiculturalismo a mosaico", que promove o desenvolvimento de comunidades separadas; ou outras políticas que reconhecem os direitos individuais mas não os grupais. Ambas abordagens apresentam limites de sucesso e de aceitação.

Porém, para o mesmo autor, uma das maiores dificuldades é o conflito entre igualdade de direitos nas diferentes tradições culturais (ver também Koopmans et al., 2005). Algumas culturas não reconhecem direitos iguais para homens, mulheres e crianças, principalmente no que se refere à união civil, educação e renda, o que contrasta com hábitos e leis de grande parte dos países democráticos. Outro fator de conflito é que alguns grupos étnicos, para manter suas tradições, cometem atos ilegais nos países que os hospedam. Podemos citar a clitoridectomia e a infibulação, ou seja, procedimentos de "castração feminina" praticada em alguns países africanos. A clitoridectomia é a mutilação dos órgãos sexuais femininos, com o corte parcial do clitóris; a infibulação é a costura dos grandes lábios vaginais, deixando apenas uma pequena abertura para as necessidades fisiológicas. Essas práticas de fins ritualísticos e religiosos são muitas vezes transportadas para outros países com a imigração. As autoridades de países receptores, agindo severamente contra essas práticas, são acusadas de preconceituosas e de não reconhecer identidades culturais.

\section{Considerações Finais}

Como visto, interculturalidade é associada a lutas por reconhecimento de identidades. Cada vez mais os países ocidentais, receptores dos fluxos migratórios atuais, enfrentam reivindicações de grupos minoritários. As transformações sociais das últimas décadas são em grande parte atribuídas ao fim do comunismo e das ideologias, que associados ao neoliberalismo e a globalização, empurraram grandes massas de pessoas para países ricos em busca de melhores condições de vida e de trabalho. Consideramos que, além desses fatores, existe uma gênese anterior para a discriminação e a intolerância étnico-religiosa atuais que é a revolução iraniana, investigada por Foucault. O filósofo estava presente no momento em que a bússola mudou de posição, do norte ideológico para a ênfase nas tradições religiosas. Sua experiência, associada a nossa vivência cotidiana com a interculturalidade na Europa, nos estimulou a escrever este artigo.

A experiência de Foucault na Pérsia como dispositivo metodológico nos permitiu a explicitação crítica de alguns pontos importantes da gênese do discurso sobre a convivência intercultural contemporânea. Não esperávamos encontrar em sua experiência sentidos ocultos ou descobrir verdades prontas a serem decifradas através de um método adequado, nem mesmo descobrir uma ordem linear da história. Buscávamos, sim, interrogar o fenômeno atual do equivocadamente chamado "choque de civilizações", pesquisando suas origens na revolução iraniana e no quanto aquele episódio liberou uma concepção de integralismo religioso inédita, que contribuiu, em conjunto com outras transformações sociais, para o atual confronto entre diferentes concepções de vida no interior dos mesmos espaços físicos e institucionais.

O que talvez fique evidente é que as dificuldades de convivência não se resumem às tradições e costumes mas, muito freqüentemente, implicam em mudanças legislativas e institucionais. Portanto, a interculturalidade não é somente uma questão de solidariedade, mas significa também a revisão de princípios de vida coletiva que não são fáceis de equacionar. As reivindicações das minorias colocam em jogo a prontidão estrutural para acolher (escolas, 
trabalho, comunicação, religião, entre outros) mas também desafiam a vontade de mudar estilos de vida. Esta zona de atrito promove a reafirmação de identidades, a delimitação de terrenos e, até mesmo, as demonstrações de força na convivência intercultural.

\section{Notas}

1 Principalmente o feminismo, o sindicalismo, o "black power", as lutas anti-instituições totais e tantos outros movimentos nascidos e/ou desaguados na primavera de 1968.

2 Pacote de leis que alteram pontos da constituição americana e autorizam interceptações, vistorias secretas, detenção de prisioneiros sem limite de tempo e sem julgamento prévio, em caso de suspeita de terrorismo. Vide campo de detenção de Guantanamo.

3 Líder da insurreição iraniana.

4 Membros do partido comunista, líderes sindicais e outros expoentes de movimentos de esquerda que se aliaram a Khomeini na revolução iraniana foram posteriormente presos e muitos enforcados em praça pública.

5 O catolicismo é dado como exemplo de religião monoteísta ocidental por constituir-se atualmente como a contraparte ao Islamismo, ou o outro pólo do chamado "choque de civilizações".

6 Votar na Itália é direito e não obrigação.

7 Jornal La Repubblica, "Sentenza del Consiglio di Stato "Lasciate i crocifissi nelle aule", 15/02/2006.

8 Localizada ao norte do país, entre as cadeias de montanhas dos Apeninos e dos Alpes, compreende regiões como a Lombardia (Milão), o Piemonte(Turim), o Veneto(Veneza) eaEmilia-Romagna (Bologna). É o coração produtivo e econômico da Itália.

9 O termo "fundamentalista" usado neste artigo não é direcionado a uma religião em específico, e sim a todas as religiões, assim como aos movimentos de conotação racista, que enaltecem credos ou etnias em detrimentos a outras. Entendemos fundamentalismo como sectarismo, como uma negação da diferença e a necessidade de se sobrepor como mais correto ou detentor da verdade.

10 Organização do Tratado Atlântico Norte.

11 Cantor de sucesso nos anos 70-80, convertido ao islamismo e atualmente Imam (líder religioso) em Londres.

\section{Referências}

Benhabib, S. (2005). La rivendicazione dell'identità culturale: eguaglianza e diversità nell'era globale. Bologna, Itália: Il Mulino.

Cavazzini, A. (2005a). Foucault in Persia. Prima e dopo il Reportage Iraniano. In Michel Foucault: L'Islam e la rivoluzione iraniana. La Rosa di Nessuno, 1.

Cavazzini, A. (2005b). Foucaulte L'Islam. In Michel Foucault: L'Islam e la rivoluzione iraniana. La Rosa di Nessuno, 1.
Crouch, C. (2003). Postdemocrazia. Bari, Itália: Laterza.

Eco, U. (2006). A passo di gambero: guerre calde e populismo mediatico. Milano, Itália: Bompiani.

Foucault, M. (2000a). Open letter to Mehdi Bazargan. In J. Faubion (Ed.), Essential Works of Foucault 1954-1984: Vol. 3. London: Penguin Books.

Foucault, M. (2000b). Useless to Revolt? In J. Faubion(Ed.), Essential Works of Foucault 1954-1984: Vol. 3. London: Penguin Books.

Huntington, S. (1993). The clash of civilizations? Foreign Affairs, 72(3), 22-49.

Jelloun, T. B. (1998). Il razzismo spiegato a mia figlia. Milano, Itália: Bompiani.

Koopmans, R., Statham, P., Giugnim M., \& Passy, F. (2005). Contested citizenship. Immigration and cultural diversity in Europe. London: University of Minnesota Press.

Lanzillo, M. L. (2005). Il multiculturalismo. Bari, Itália: Laterza.

Lerner, G. (2005). Tu sei un bastardo. Contro l'abuso delle identità. Milano, Itália: Feltrinelli.

Mantovani, G. (2004). Intercultura: è possibile evitare le guerre culturali? Bologna, Itália: Il Mulino.

Rodrigues, M. B. (2005, set./dez.). Quais são as nossas diferenças? Reflexões sobre a convivência com o diverso em escolas italianas. Psicologia e Sociedade, 17(3), 57-61.

Sartori, G. (2007). Pluralismo, multiculturalismo e estranei. Saggio sulla società multietnica. Milano, Itália: RCS Libri.

Todorov, T. (2005). Diritto d'ingerenza o dovere di assistenza? In S. Sontag, T. Tzvetan \& M. Ignatieff(Eds.), Troppo Umano. Milano, Itália: Mondatori.

Maria Beatriz Rodrigues é $\mathrm{PhD}$ em Development Studies, Sussex University (GB). Psicóloga e Educadora em Gênova (Itália), trabalha em cooperativas sociais com diversidade, interculturalidade e inclusão. Endereço para correspondência: Via Barassi, 5 B, 16033, Lavagna (GE), Itália. Tel. 00390185390931. biarodrigues@hotmail.it

\section{Interculturalidade: por uma genealogia da discriminação}

Maria Beatriz Rodrigues

Recebido: 15/5/2007

$1^{\text {a }}$ revisão: 9/7/2007

$2^{\mathrm{a}}$ revisão: 5/9/2007

Aceite final: 12/9/2007 